\title{
Detection of a Point Mutation at Codon 12 of the Kirsten-Ras (K-ras) Oncogen in Myelodysplastic Syndrome
}

\author{
Howida M. Sharaf, Nihal S. El-Kinawy, Ayman Omar* and Manal A. Ali** \\ Clinical Pathology Department, Ain Shams University Hospitals \\ Internal Medicine Department Wadi El-Neel Hospital* and Ain Shams Specialized Hospital
}

\begin{abstract}
Background: Mutations in ras genes have been observed in a variety of cancers and were found to play an important role in human leukemogenesis and in preleukemic disease as myelodysplastic syndrome (MDS). The purpose of this study was to determine the prevalence of mutated K-ras oncogene in myelodysplastic syndrome (MDS); with a special emphasis on their possible role in affecting clinical status, relation to karyotypic pattern; response to therapeutic measures; its impact on the fate of the disease and overall survival.
\end{abstract}

Subjects \& methods: Detection of point mutation of Kirsten-ras (K-ras) gene in 30 patients suffering from myelodysplastic syndrome was carried out using quantitative enriched polymerase chain reaction (QEPCR) and was confirmed by sequencing. QEPCR is a two- stage PCR procedure with modified primers that enriches mutant alleles, via restriction endonuclease digestion of normal alleles and enables identification of one mutant allele among 100,000 normal alleles.

Results: Activating mutations of the codon 12 of K-ras gene were detected in 7/30 (23.3\%)cases of MDS, the most common mutation involved a substitution of aspartic acid for glycine (GGT $\rightarrow$ GAT). The incidence of K-ras mutations was found to be significantly associated with refractory anemia with excess blasts type II (RAEBII) and unclassified (UC) MDS than other subtypes ( $\mathrm{p}=0.005$ ), and was significantly associated with hypercellular bone marrow ( $\mathrm{p}=0.04$ ) showing marked dyserythropoitic changes. Furthermore, mutant K-ras gene was found to be significantly associated with abnormal karyotypes ( $\mathrm{p}=0.04)$. Patients with mutated K-ras gene were significantly associated with either high or intermediate risk according to International Prognostic Scoring System (IPSS) ( $\mathrm{p}=0.001) .6 / 7(85.7 \%)$ of those carrying the mutation showed poor response to treatment compared to non carriers with a statistical significant difference ( $\mathrm{p}=0.009)$. Five out of eight (62.5\%) patients who were transformed to AML carried the mutant K-ras gene, their subtypes were RAEBII and unclassified MDS with abnormal cytogenetics mainly Monosomy 7. Overall survival was detected using Kaplan-Meier curve and the mean survival time of patients who carried K-ras mutations were significantly lower than those without the mutation (Log rank test=12.7; p=0.0004).

Conclusion: MDS patients bearing an mutated K-ras oncogene frequently showed poor response to treatment; leukemic progression of the disease and shorter overall survival, suggesting that an activated $\mathrm{K}$-ras oncogene is a critical factor for prognostic evaluation; therapeutic decision and monitoring of response to treatment of MDS patients.

Key words: K-ras, QEPCR, MDS.

\section{Introduction}

Ras genes encode a family of 21-kd proteins (H-ras, K-ras, and N-ras)( Liu et al., 1987) They play a role in signal transduction thus regulating cell proliferation, differentiation, and survival (Lièvre $\boldsymbol{e t}$ al., 2008) Mutations in these genes usually result from single amino acid substitutions at one of the 
critical regions of the protein. These mutations have been detected in codon 12 or 13 of the ras gene

(Amado et al., 2008) They are activating mutations and have been observed in a variety of cancers resulting in continual signal transduction and stimulation of downstream signaling pathways involved in cell growth, proliferation, invasion, and metastasis (Eberhard et al., 2005)

Myelodysplastic syndromes (MDS) are clinically heterogenous disorders characterized by clonal hematopoiesis, impaired differentiation, peripheral blood cytopenias and a risk of progression to acute myloid leukemia (AML) (Ohara et al.,2002) Somatic mutations may influence its clinical phenotype and overall survival(Ahuja et $\boldsymbol{a l . , 1 9 9 0 \& ~}$

Bejar et al., 2011)An understanding of the effects of mutations in various genes as ras genes could improve the prediction of prognosis in these patients and inform for the selection of specific therapies

(Nakagawa et al.,1992 \& Sekeres ,2010).

In view of such data, the purpose of this study was to determine the prevalence of activated K-ras oncogene in MDS patients; with a special emphasis on their possible role in affecting clinical status, response to therapeutic measures; impact on the fate of the disease and overall survival.

\section{Subjects and Methods:}

This study included 30 MDS patients attending Hematology Unit, Ain Shams University and Wadi El-Neel Hospitals from September 2007 to September 2010. They were 19 males and 11 females with a ratio of 1.7:1. Their age ranged from 21-67 years with a mean age of 42 years. The diagnosis was based on standard clinical and haematological criteria using histopathology, cytochemistry and cytogenetic analysis(Nosslinger et al., 2000).

All patients were subjected to the following:
-Thorough history taking and clinical examination laying stress on hepatomegaly, splenomegaly and lymphadenopathy.

-Complete blood counts using Coulter Gen S (Coulter Electronics,USA) and leishman stained blood smears. -Bone marrow (BM) aspiration and trephine biopsy examination

-Conventional Cytogenetic analysis (CCA) by Gbanding (Haase et al., 2007).

-Mutant K-ras codon 12 alleles detection by Quantitative Enriched Polymerase chain reaction (QEPCR) followed by DNA sequencing (Ronai and Minamoto,1997).

MDS patients were divided into 3 risk groups according to International Prognostic Scoring System (IPSS) criteria(Garcia-Manero et al., 2008)as regards BM blasts \% $(<5 \%, 5-10 \%, 11-19 \%$ $\&>20 \%)$, Cytopenias $(\mathrm{Hb}<10 \mathrm{~g} / \mathrm{dl}$, neutrophils $<1.5 \times 10^{9} / \mathrm{L}$ and platelet $<100 \times 10^{9} / \mathrm{L}$ ) (Ohara et al.,2002 ) and Karyotype pattern (low risk patients with normal karyotype, chromosome y deletion, del (20q), del (5q)); high risk patients with chromosome 7 anomalies or complex karyotype (3 abnormalities) and intermediate risk patients with any other anomalies as trisomy 8 , single or double abnormality).

Treatment strategy was by: Supportive treatment: (irradiated packed RBCs with symptomatic anemia or $\mathrm{Hb}<8 \mathrm{~g} / \mathrm{dL}$; platelets concentrates with active bleeding or platelet count $\left.<10 \times 10^{9} / \mathrm{L}\right)$; Hemopoietic growth factor and folic acid; others (immunotherapy, chemotherapy or combined), Bone marrow and stem cell transplantation.

Patients were followed up for 36 months for evaluation of: treatment response by repeated complete blood counts and bone marrow aspirate, complete response and relapse were defined according to standard criteria (List,2008). Assessment 
of overall survival (OS) was analyzed by KaplanMeier curves and Log Rank test. Overall survival was measured from day of diagnosis until death from any cause, or patients known to be alive at last contact.

\section{Sampling}

For detection of K-ras mutation by QEPCR: Five milliliters bone marrow or 5-10 ml peripheral blood was collected on EDTA. For cytogenetic analysis: $1 \mathrm{ml} \mathrm{BM}$ in sterile, preservative-free-heparin, coated vacutainer tube. Samples were collected after informed consent.

\section{Methods}

\section{Conventional cytogenetic analysis (CGA) by G-} banding :

This analysis involves the examination of spontaneously dividing cell populations by blocking cell division at metaphase stage with an inhibitor of spindle formation (colcemid). This is followed by hypotonic wash and fixation then slide making and staining with Giemsa stain using trypsin to induce Gbanding. Analysis of available metaphase was performed using light microscope and image system.

Mutant K-ras codon 12 allele detection:

Quantitative Enriched Polymerase chain reaction (QEPCR)

QEPCR is two steps PCR procedure involving an initial PCR of K-ras target, restriction digest of wild type sequences followed by a second PCR that amplifies remaining mutant target sequence. -DNA extraction: Genomic DNA was isolated using QIAamp DNA Minikit (Qiagen, Germany) according to manufacturer's instructions and stored at $-80^{\circ} \mathrm{C}$ until used.

-PCR amplification: Fragment encompassing exon 1 of human K-ras gene was amplified by QEPCR. Primers used for first round PCR were: Forward primer: 5'-GCG GTT GGG GCT TAA TTG CAT ATA AAC TGA ATA TAA ACT TGT GGT AGT TGG ACCT-3'.

Reverse primer: 5'-GCT GTT GTC ATA GTA ATG ATC TCA TTC CAV TGT ACT CCT C-3'.

Primers used for 2 nd round PCR were: Forward primer: 5'-GCG GTT GGG GCT TAA TTGCA-3'. Reverse primer: 5'-GCT GTT GTC ATA GTA ATG AT-3'.

During the first round of amplification the reaction was carried out in a total volume of $50 \mathrm{ul}$ containing $1 \mathrm{ug}$ of genomic DNA, 0.12pmol/ul of each primer, $0.2 \mathrm{mM}$ of each dNTPs, 0.5 unit thermostable Taq DNA polymerase and $1 \mathrm{X}$ Reaction buffer (all reagents were supplied by Promega, USA). Cycling consisted of 20 cycles: denaturation $94^{\circ} \mathrm{C}$ for 1 minute, annealing $59^{\circ} \mathrm{C}$ for 1 minute, extension $72^{\circ} \mathrm{C}$ for 1 minute and finally another 5 minutes at $72^{\circ} \mathrm{C} .5 \mathrm{ul}$ of amplified material was used for restriction enzyme digestion using MVaI (12 units) supplied by (Boehringer Mannheim Biochemica) and respective buffer in total volume of 20 ul for 2 hours at $37^{\circ} \mathrm{C}$

From the digested material $5 \mathrm{ul}$ was taken for the second amplification using $0.12 \mathrm{pmol} / \mathrm{ul}$ of each primer of second round. Other reaction and cycling conditions were as for the first round. 2\% Agrose gel electrophoresis was used to confirm the product of amplification with $190 \mathrm{bp}$ for the mutant gene, 146 bp for the wild type. Normal samples were included in each run (Fig1).

\section{DNA Sequencing of mutated cases}

Product from the second PCR was used for DNA sequencing. Mutated samples were sequenced with the primers used in the second QEPCR reaction. Sequencing with a dye terminator cycle sequencing kit (Applied Biosystems,UK) following the manufacture's instruction. The sequences were 
analyzed on an ABI PRISM 310 genetic analyzer, Perkin Elmer (Applied Biosystems, UK). (Fig1).

\section{Statistical analysis}

It was performed by using SPSS 9 statistical software on IBM compatible PC. Continuous data parameters were described as mean $\pm \mathrm{SD}$. For comparative study, chi- square $\left(\mathrm{X}^{2}\right)$ test for non parametric data and Student $t(t)$ test for parametric data were used. Survival analysis was performed using Kaplan Meier curves and Log Rank test. The probability (p value) was considered significant if $\mathrm{p}<0.05$.

\section{Results}

Demographic, clinical characteristics and laboratory data of the study patients are detailed in tables $1 \& 2$. Clinically $36.7 \%$ had organomegaly while $13.3 \%$ had lymphadenopathy.

Peripheral blood picture showed that $50 \%$ of the patients suffered of pancytopenia while $43.3 \%$ were bicytopenic and 2 patients had anemia only. Bone marrow was hypercellular in $40 \%$ of cases, hypocellular in $26.7 \%$ and normocellular in $33.3 \%$. The BM examination showed dyserythropoiesis in $63.3 \%$, dysgranulopoiesis in $33.3 \%$ and dysmegakaryopoiesis in $16.7 \%$. According to WHO classification; refractory anemia (RA) was diagnosed in $53.3 \%$ of patients; refractory anemia with ringed sideroblasts (RARS) in $6.7 \%$; refractory anemia with excess blasts type I (RAEBI) in 10\%, refractory anemia with excess blasts type II (RAEBII) in $20 \%$, refractory cytopenia with multiple dysplasia (RCMD) in 6.7\%, unclassified (UC) MDS in 3.3\% (Table1). Cytogenetic analysis showed a normal karyotype in $18(60 \%)$ of patients, whereas chromosomal abnormalities were observed in $12(40 \%)$ patients. The most frequent karyotype was monosomy 7 which was observed in 4/12 (33.3\%) cases. 5q- was detected in 2 patients; trisomy 8 was in 2 patients; trisomy 21 was in 1 case; del 17 in 1 case while 2 cases showed complex karyotype.

IPSS risk classification had been ascertained at the time of diagnosis. Accordingly, our MDS patients were classified into 3 prognostic groups: 46.7\% (14 patients) were low risk most of them had RA with normal karyotype. $36.7 \%$ (11 cases) showed intermediate risk with various MDS subtypes, 7 of which showed abnormal karyotypes: 2 had trisomy 8 , 1 case had trisomy 21, 1 case had del 17, 2 cases had 5q-and 1 had complex karyotype (combined del 3 \& del 6). Five (16.7\%) cases were classified as highrisk. They carried chromosomal abnormalities (monosomy $7 \&$ complex karyotype) and were associated with RAEBII and unclassified MDS.

Of the 30 MDS patients included in this study, seven $(23.3 \%)$ were positive for point mutations of the K-ras gene at exon 1, codon 12. All mutated cases detected by QEPCR were confirmed by DNA sequencing. The nature of the point mutations involved a substitution of aspartic acid for glycine $(\mathrm{GGT} \rightarrow \mathrm{GAT})$ in 6 patients. Only one patient showed a substitution of argenine for glycine (GGT $\rightarrow \mathrm{GCT})$. Normal samples were included in each run and were negative for K-ras mutations. According to presence and absence of the mutation, the clinical characteristics and laboratory data of patients were compared. The incidence of K-ras mutations was found to be significantly associated with RAEBII and UC subtypes $(\mathrm{p}=0.005)$ and was associated with bone marrow hypercellularity ( $\mathrm{p}=0.04$ ), moreover $85.7 \%$ of patients with mutant K-ras showed marked dyserythropoitic changes. Again $71.4 \%$ of patients carry K-ras mutation were found to have abnormal karyotype with a statistical significant difference $(\mathrm{p}=0.04)$. They were significantly associated with high and intermediate risk classification according to IPSS ( $\mathrm{p}=0.001)$. Moreover they were significantly associated with poor response to treatment $((\mathrm{p}=0.009 ;$ Table 1$)$. Patients with K-ras mutations were more likely to have elevated blast percentage with a statistical significant difference ( $\mathrm{t}=2.89 ; \mathrm{p}=0.007)$, but the two groups did not differ significantly with respect to leucopenia, anemia or thrombocytopenia ( $p>0.05$; Table2). On following up of the patients, $63.3 \%$ showed favorable response to treatment (complete remission or stable disease) while $36.7 \%$ showed unfavorable response (incomplete remission, relapse or treatment failure). Presence of K-ras was significantly associated with unfavorable response to treatment as $85.7 \%(6 / 7)$ of 
those carrying the mutation showed unfavorable response to therapy $(\mathrm{p}=0.009$; Table 1$)$.

Moreover, 8 (26.7\%) of MDS patients evolved to AML (BM blasts $>20 \%$ ). It occurred mainly in patients having hypercellular marrow. $5 / 8(62.5 \%)$ of them carried mutated K-ras gene, with RAEBII and unclassified MDS. By the end of the study, $70 \%$ of cases lived and $30 \%$ died. K-ras mutation was statistically associated with the fate of the patients as 5 of the $7(71.4 \%)$ cases carrying the K-ras mutation

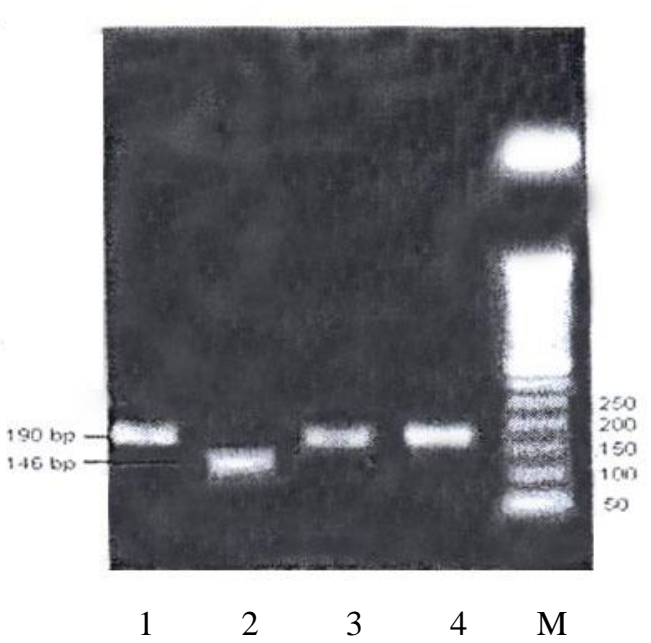

Photo1: Electrophoretic separation of PCR amplification product Lanes 1,3,4: mutant type of K-ras Lane 2: wild type of K-ras. M: molecular marker



(a)

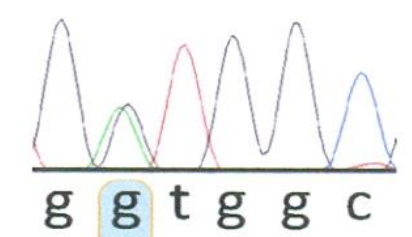

(b)
$\operatorname{died}\left(\mathrm{X}^{2}=5.96 ; \mathrm{p}=0.01\right)$ and the risk estimation for the presence of K-ras mutation showed an odd ratio of 1.8. Kaplan-Meier analysis of overall survival showed that the mean survival of patients with nonmutated K-ras gene was 23.4 months with $95 \%$ CI (20.1-26.8) while patients with mutated K-ras showed a mean survival of 14.8 months with $95 \%$ CI (9.5-17.5) and a Log Rank test of 14.7 showing a high statistical significant difference $(\mathrm{p}=0.0001 ;$ Figure 2$)$.

Fig.1: DNA sequence analysis for K-ras gene at codon 12
(a) wild type of K-ras.
(b) G to A mutation.
(c) G to $\mathrm{C}$ mutation. 
Table (1): Patients characteristics according to presence or absence of K-ras

\begin{tabular}{|c|c|c|c|c|c|}
\hline \multirow[b]{2}{*}{$\begin{array}{l}\text { Parameters } \\
\qquad(\mathrm{n}=30)\end{array}$} & & \multicolumn{2}{|c|}{ K-ras } & \multirow[b]{2}{*}{$\mathrm{X}^{2}$} & \multirow[b]{2}{*}{$\mathrm{p}$} \\
\hline & & $\begin{array}{c}\text { Non-mutant(23) } \\
\mathrm{n}(\%)\end{array}$ & $\begin{array}{c}\text { Mutant(7) } \\
\mathrm{n}(\%)\end{array}$ & & \\
\hline Sex & & & & & \\
\hline Male & (19) & $13(56.5)$ & $6(85.7)$ & 10r & 0015 \\
\hline Female & (11) & $10(43.5)$ & $1(14.3)$ & & \\
\hline \multicolumn{2}{|l|}{ Organomegaly } & & & \multirow{3}{*}{0.15} & \multirow{3}{*}{0.65} \\
\hline -ve & (19) & $15(65.2)$ & $4(57.1)$ & & \\
\hline$+\mathrm{ve}$ & (11) & $8(34.8)$ & $3(42.9)$ & & \\
\hline \multicolumn{2}{|l|}{ Lymphadenopathy } & & & \multirow{3}{*}{0.01} & \multirow{3}{*}{0.93} \\
\hline$-v e$ & (26) & $20(87)$ & $6(85.7)$ & & \\
\hline +ve & (4) & $3(13)$ & $1(14.3)$ & & \\
\hline \multicolumn{2}{|l|}{ Cytopenia } & & & \multirow{4}{*}{1.906} & \multirow{4}{*}{0.38} \\
\hline Anemia & (2) & $2(8.7)$ & - & & \\
\hline Bicytopenia & (13) & $11(47.8)$ & $2(28.6)$ & & \\
\hline Pancytopenia & $(15)$ & $10(43.5)$ & $5(71.4)$ & & \\
\hline \multicolumn{2}{|l|}{ MDS type } & & & \multirow{7}{*}{16.9} & \multirow{7}{*}{$0.005^{*}$} \\
\hline RA & (16) & $16(69.5)$ & - & & \\
\hline RARS & (2) & $1(4.3)$ & $1(14.3)$ & & \\
\hline RAEB I & (3) & $3(13)$ & - & & \\
\hline RAEB II & (6) & 2(8.6) & $4(57.1)$ & & \\
\hline RCMD & (2) & $1(4.3)$ & $1(14.3)$ & & \\
\hline $\mathrm{UC}$ & (1) & - & $1(14.3)$ & & \\
\hline \multicolumn{2}{|l|}{ BM celularity } & & & \multirow{4}{*}{6.05} & \multirow{4}{*}{$0.04 *$} \\
\hline Normo & (10) & $10(43.5)$ & - & & \\
\hline Hypocellular & $(8)$ & $7(30.4)$ & $2(28.6)$ & & \\
\hline Hypercellular & $(12)$ & $6(26.1)$ & $5(71.4)$ & & \\
\hline \multicolumn{2}{|l|}{ Cytogenetics } & & & \multirow{3}{*}{3.89} & \multirow{3}{*}{$0.04 *$} \\
\hline Normal & (18) & $16(69.6)$ & $2(28.6)$ & & \\
\hline Abnormal & (12) & $7(30.4)$ & $5(71.4)$ & & \\
\hline \multicolumn{2}{|l|}{ IPSS Risk } & & & \multirow{4}{*}{13.3} & \multirow{4}{*}{$0.001 *$} \\
\hline Low & (14) & $14(60.9)$ & - & & \\
\hline Intermediate & (11) & $8(34.8)$ & $3(42.9)$ & & \\
\hline High & (5) & $1(4.3)$ & $4(57.1)$ & & \\
\hline $\begin{array}{c}\text { Response to ttt } \\
\text { Favorable } \\
\text { Unfavorable }\end{array}$ & $\begin{array}{l}(19) \\
(11)\end{array}$ & $\begin{array}{c}18(78.3) \\
5(21.7)\end{array}$ & $\begin{array}{l}1(14.3) \\
6(85.7)\end{array}$ & 6.904 & $0.009 *$ \\
\hline
\end{tabular}

RA:refractory anemia. RAEB:refractory anemia with excess blasts. RARS:refractory anemia with ringed sideroblasts. RCMD: refractory cytopenia with multiple dysplasia. UC: unclassified. IPSS:International Prognostic Scoring System; $\mathrm{ttt}:$ treatment.*Significance level $\mathrm{p}<0.05$. 
Table (2): Comparison between laboratory results according to presence or absence of K-ras

\begin{tabular}{|l|c|l|l|l|}
\hline \multirow{2}{*}{$\begin{array}{l}\text { Parameters } \\
(\mathrm{n}=30)\end{array}$} & \multicolumn{2}{|l|}{ K-ras } & $\mathrm{t}$ & $\mathrm{p}$ \\
\cline { 2 - 4 } & $\begin{array}{l}\text { Non-mutant } \\
(\text { mean } \pm \text { SD })\end{array}$ & $\begin{array}{l}\text { Mutant } \\
(\text { mean } \pm \text { SD })\end{array}$ & & \\
\hline Age $(\mathrm{y})$ & $40 \pm 2.2$ & $47 \pm 6.5$ & 1.28 & 0.21 \\
\hline $\mathrm{TLC} \quad\left(\mathrm{x} 10^{9} / \mathrm{L}\right)$ & $5.1 \pm 1.3$ & $3.3 \pm 1.5$ & 1.02 & 0.91 \\
\hline $\mathrm{Hb} \quad(\mathrm{gm} / \mathrm{dl})$ & $8.1 \pm 1.9$ & $8.2 \pm 0.7$ & 0.013 & 0.98 \\
\hline Platlets $\left(\mathrm{x} 10^{9} / \mathrm{L}\right)$ & $87.3 \pm 15.4$ & $101.7 \pm 46$ & 0.38 & 0.704 \\
\hline BMblast $(\%)$ & $5.9 \pm 3.2$ & $30.2 \pm 11.2$ & 2.89 & $0.007^{*}$ \\
\hline
\end{tabular}

SD:Standard deviation; TLC: total leucocytic count; Hb:hemoglobin; BM:bone marrow ${ }^{*}$ Significance level $\mathrm{p}<0.05$.

\section{Survival Functions}

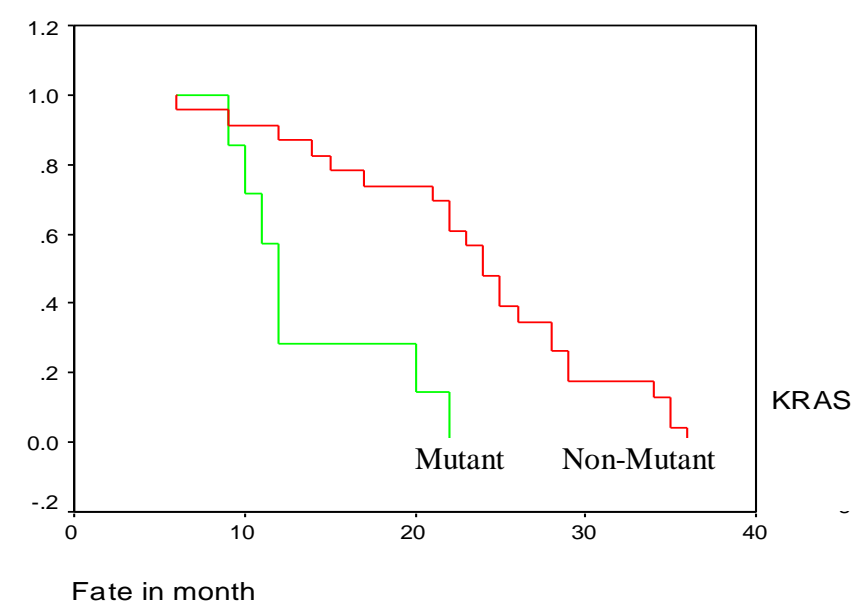

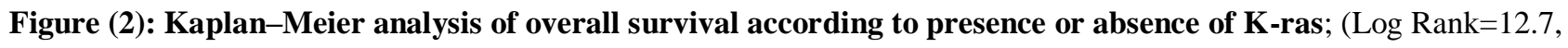
$\mathrm{p}=0.0004)$.

\section{Discussion}

K-ras oncogenes activated by point mutation have been frequently detected in various types of human cancers (Rocquain et al., 2010 ) .Analysis of a large number of leukemias revealed that activated K-ras oncogenes were observed preferentially in AML, T-ALL and Null-ALL. These results suggest that K-ras oncogenes play an important role in human leukemogenesis (Liu et al., 1987 ).Activated K-ras oncogenes were also detected in myelodysplastic syndrome (MDS) which is considered to be a preleukemic disease (Rocquain et al., 2010 ).

In the present study the K-ras point mutation in exon 1 , codon 12 was detected in $23.3 \%$ of cases, in close agreement to that reported previously (Harada \&Harada ,2011 ) but differs from those reported by other researchers who showed different frequencies ranging from $0 \%$ up to $40 \%$. This discrepancy may reflect the variable sensitivities and specificities of different techniques used or may reflect heterogenity in the patient populations studied (Ronai $\&$

\section{Minamoto , 1997).}

Several investigators have suggested that there is a heterogeneity of leukemic cells with respect to the presence of activated ras gene and that in some patients only a fraction of malignant cells carry the mutant gene (Farr et al.,1988 )this was explained by 
that the mutation occurs later after a preleukemic clone has already emerged thus giving the premalignant clone an additional growth advantage. An alternative explanation was that the ras mutation occurred early in the preleukemic process and that there was later evolution with the emergence of a clone which has been activated by another gene

(Nakagawa et al., 1992).

Furthermore, in this report the most common mutation was involving a substitution of aspartic acid for glycine (GGT $\rightarrow \mathrm{GAT}$ ), this was in accordance to a previous report(Liu et al.,1987) which explained that this may reflect either involvement of a specific unknown mutagen or selective advantage offered in vivo by this mutation in the ras protein (Bejar et al.,2011).

In this study, K-ras mutation strongly associates with RAEBII subtype and with BM hypercellularity. Again, our results showed that $85.7 \%$ of patients with positive K-ras suffered of marked dyserythropoitic changes this finding is consistent with and support the notion that mutant $\mathrm{K}$ ras directly impairs erythropoiesis in patients with MDS, as transduction of human erythroid progenitors with oncogenic ras results in hyperproliferation but with defective differentiation resulting in reduced production of mature erythrocytes (Nakagawa et al., 1992 ).

In the current study, patients with K-ras mutations were more likely to have elevated blast percentage than the non mutant cases with a significant difference $(\mathrm{p}=0.007)$, but the two groups did not differ significantly with respect to leucopenia, anemia or thrombocytopenia as previously reported (Ahuja et al.,1990).

Again in this report, K-ras mutation was found to be significantly associated with abnormal karyotypes as $71.4 \%$ of patients carrying the mutation showed abnormal karyotypes; moreover the presence of the mutation was strongly associated with high risk ( $\mathrm{p}=0.001)$. Thus denoting the importance of $\mathrm{K}$-ras mutation in MDS and its prognostic significance (Bejar et al., 2011).

In the present report, following up, of cases showed favorable response in $63.3 \%$ while $36.7 \%$ showed failure of treatment. $85.7 \%$ of those carrying the mutation showed poor response to treatment as previously reported (List ,2008) showing that K-ras mutations at exon 1 codon 12 have been associated with lack of response to therapeutic agents targeted to signaling pathways which are regulated by K-ras protein, thus recommending to test $\mathrm{K}$-ras mutation before initiating these therapies furthermore alternative therapies should be considered for patients with K-ras mutations (Linardou et al.,2008).

In this report, 8 patients transformed to AML, 5 of them carried the mutant K-ras gene, and their subtypes were RAEBII and unclassified MDS. Additionally, their previous bone marrow examination showed mainly hypercellularity. This is in agreement with previous studies (Amado et

al., 2008 \& Harada and Harada 2011) showing that MDS patients with mutations may evolve to AML more frequently than those without mutations. Conversely, other observers found reduction of mutant K-ras gene with leukemic transformation (Kosmider et al., 2010).

Furthermore, the existence of ras mutations in diverse myeloid malignancies raises the possibility that they invariably represent secondary events that cooperate with a spectrum of initiating genetic lesions. Consistent with this possibility, it was found that some AMLs contain subclones with independent ras mutations moreover other ras mutations that are detected at diagnosis may disappear over time in patients 
with persistent or relapsed disease (Malcovati $\boldsymbol{e t}$ al., 2007\& Bejar et al.,2011). Other investigators found that patients who progressed to AML without K-ras mutation may carry transforming gene other than K-ras (Ahuja et al., 1990 ). Thus it was proposed that the presence of K-ras gene mutation may be of prognostic value. However there are other factors which are important in prognosis. Also, in the present study we found that hyperplastic marrow had a significantly high frequency of progress to AML as previously reported (Sakuma et al., 2006 ). Moreover, our results showed that RA and RARS typically have the lowest incidence of leukemic evolution, whereas RAEB is the highest, this is in accordance to a previous study (Pardanani et al.,2010).

By the end of this work, $70 \%$ of patients lived while $30 \%$ died. 5 of the 7 (71.4\%) cases carrying the K-ras mutation died. Survival analysis confirmed the

\section{References}

1) Ahuja H G, Foti A, Bar-Eli M, and Cline MJ (1990): The Pattern of Mutational Involvement of RAS Genes in Human Hematologic Malignancies Determined by DNA Amplification and Direct Sequencing. Blood; 75, (8):1684-1690.

2) Amado RG, Wolf $M$ and Peeters $M$ (2008): Wildtype KRAS is required for panitumumab efficacy in patients with metastatic colorectal cancer. J Clin Oncol; 26:1626-1634.

3) Bejar R, Stevenson K, Abdel-Wahab O, Galili N and Nilsson B (2011): Clinical Effect of Point Mutations in Myelodysplastic Syndromes N Engl J Med; 364:2496-2506.

4) Bejar R, Levine R and Ebert BL (2011): Unraveling the molecular pathophysiology of myelodysplastic syndromes. J Clin Oncol;29:504-515.

5) Eberhard DA, Johnson BE and Amler LC (2005): Mutations in the epidermal growth factor receptor and in $K R A S$ are predictive and prognostic indicators in prognostic validity of K-ras, as the risk estimate for K-ras showed high odd ratio of (1.8).

Kaplan-Meier analysis of overall survival showed the mean survival of patients with nonmutated K-ras was 23.4 months compared to14.8 months months in patients with mutated K-ras showing a high statistical significant difference $(\mathrm{p}=0.0001)$. Similar results were obtained previously (Bejar et al., 2011 ).

In conclusion, MDS patients bearing a mutated K-ras oncogene frequently showed poor response to treatment; leukemic progression of the disease and shorter overall survival, suggesting that an activated $\mathrm{K}$-ras oncogene is a critical factor for prognostic evaluation; therapeutic decision and monitoring of response to treatment of MDS patients.

patients with non-small-cell lung cancer treated with chemotherapy alone and in combination with erlotinib. J Clin Oncol; 25:5900-5909.

6) Farr CJ, Saiki RK, Erlich HA and McCormick F (1988): Analysis of ras gene mutations in acute myeloid leukaemia by polymerase chain reaction and oligonucleotide probes. Proc Nat! Acad Sci USA; 85:1629-1633.

7) Garcia-Manero G, Shan J and Faderl S (2008): A prognostic score for patients with lower risk myelodysplastic syndrome. Leukemia; 22:538-543.

8) Haase D, Germing U and Schanz J (2007): New insights into the prognostic impact of the karyotype in MDS and correlation with subtypes: evidence from a core data set of 2124 patients. Blood; 10:4385-4395.

9) Harada Y and Harada H (2011): Molecular mechanisms that produce secondary MDS/AML by RUN/AML1 point mutations. J. cell Biochem; 112(2):425-32. 
10) Kosmider O, Gelsi-Boyer V and Slama L (2010):

Mutations of IDH1 and IDH2 genes in early and accelerated phases of myelodysplastic syndromes and MDS/myeloproliferative neoplasms. Leukemia; 24:1094-1096.

11) Lièvre A, Bachet J-B and Boige V (2008): KRAS mutations as an independent prognostic factor in patients with advanced colorectal cancer treated with cetuximab. J Clin Oncol; 26:374-379.

12) Linardou H, Dahabreh IJ, Kanaloupiti D et al. (2008): Assessment of somatic K-ras mutations as a mechanism associated with resistance to EGFRtargeted agents: a systematic review and meta-analysis of studies in advanced non-small-cell lung cancer and metastatic colorectal cancer. Lancet Oncology; 9:962972.

13) List A.F. (2008): New agents in treatment of MDS. Leuk Res; 31(Suppl 1):S37-S38.

14) Liu E, Hjelle B, Morgan R, Hecht F and Bishop JM (1987): Mutations of the Kirsten-ras protooncogene in human preleukemia. Nature; 300:186191.

15) Malcovati L, Germing U, Kuendgen A, et al. (2007): Time-dependent prognostic scoring system for predicting survival and leukemic evolution in myelodysplastic syndromes. J Clin Oncol; 25:35033510 .

16) Nakagawa T, Saitoh S, Imoto $S$, Itoh M, Tsutsumi M, et al. (1992): Multiple point mutation of N-ras and K-ras oncogenes in myelodysplastic syndrome and acute myelogenous leukemia. Oncology; 49(2):11422.

17) Nosslinger T., Reisner R., Roller E. and Gruner H. (2000): Myelodysplastic syndrome from FAB to WHO classification comparison of classification on
431 unselected patients from single institution. Blood; 93:2935-39.

18) Ohara A, Kojima S, Okamura J, et al. (2002): Evolution of myelodysplastic syndrome and acute myelogenous leukaemia in children with hepatitisassociated aplastic anaemia. Br J Haematol;116(1):514.

19) Pardanani A, Patnaik MM, Lasho TL, et al. (2010): Recurrent IDH mutations in high-risk myelodysplastic syndrome or acute myeloid leukemia with isolated $\operatorname{del}(5 q)$. Leukemia; 24:1370-1372.

20) Ronai $\mathbf{Z}$ and Minamoto $T$ (1997): Quantitative enriched PCR (QEPCR), a highly sensitive method for determination of K-ras oncogene mutation. Hum Mutat; 10(4):322-5.

21) Sakuma T, Hayashi $\mathbf{Y}$, Kanomata $\mathbf{N}$ and Murayama T (2006): Histological and cytogenetic characterization of bone marrow in relation to prognosis and diagnosis of myelodysplastic syndromes. Pathol Int; 56(4):I91-9.

22) Schubbert S, Bollag G, Lyubynska N, Nguyen H, et al (2007): Biochemical and Functional

Characterization of Germ Line K-ras Mutations. Mol Cell Biol; 27(22):7765-7770.

23) Sekeres MA. (2010): The epidemiology of myelodysplastic syndromes. Hematol Oncol Clin North Am; 24:287-294.

24) Rocquain J, Carbuccia N, Trouplin V, et al (2010): Combined mutations of ASXL1, CBL, FLT3, IDH1, IDH2, JAK2, K-ras, NPM1, NRAS, RUNX1, TET2 and WT1 genes in myelodysplastic syndromes and acute myeloid leukemias. BMC Cancer; 10:401-401. 


\section{تقييم التحول الجينى للK-ras فى رامزة 12 لمرضى متلازمة سوء النمو النخاعي \\ د/هويدا محمد شرف* د. نهال سعد القتاوى* د. أيمن عمر محمود *** د. منال عبد الحميد على*** \\ قسم الباثولوجيا الأكلينيكية_ مستشفيات جامعة عين شمس* ـ قسم الباطنة مستشفى وادى النيل** ـ قسم الباطنة مستشفى عين شمس \\ التخصصى}



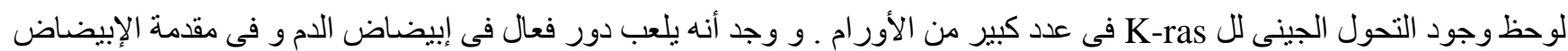

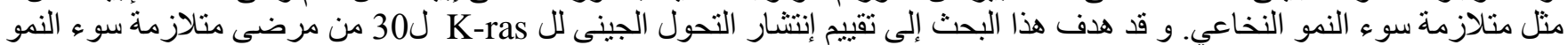

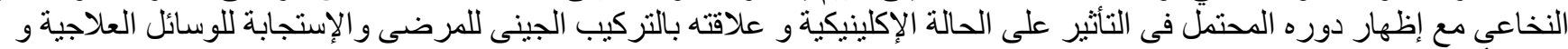

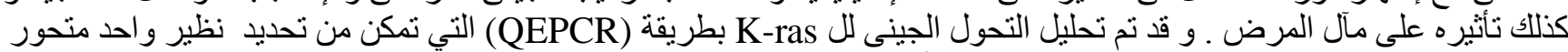

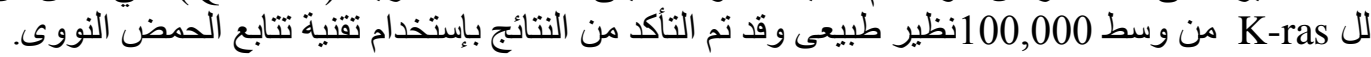

النتائج:

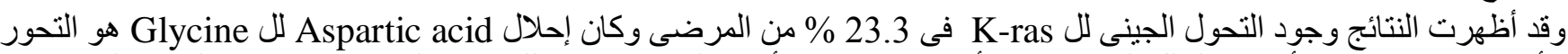



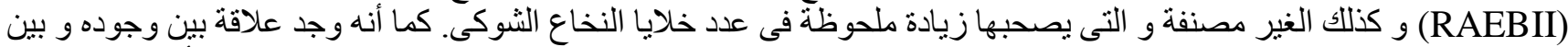

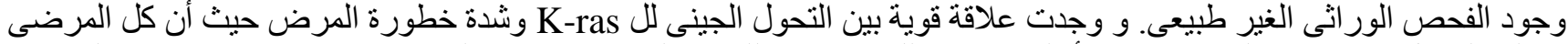

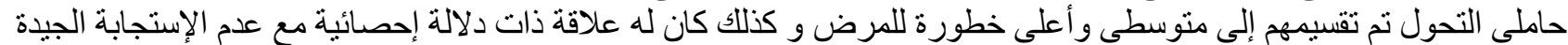

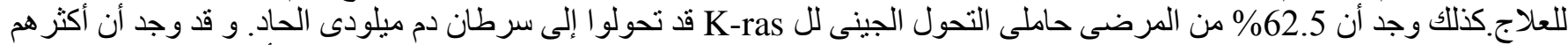

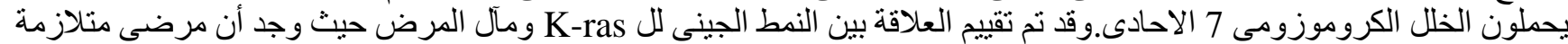
ذو ء النمو النخاعى حاملى التحول الجينى كانو ا أقل فى متوسط زمن البقاء بالمقارنة مع غير الحاملين لهذا التحول الجينى مع وجود فرق النقال ذو دلالة إحصائية.

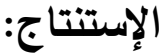

وقد خلص هذا البحث إلى أن مرضى متلازمة سوء النمو النخاعى الذين يحملون التحول الجينى لل K-ras في أغلب الأحيان

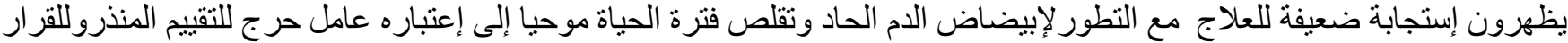

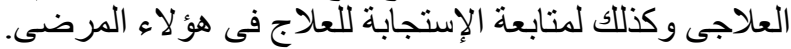

